\title{
FORECASTING THE BUILDING DEFORMATION USING THE NON-EQUIDISTANCE GREY MODEL $(1,1)$
}

\author{
Aleksandar Milutinović1 ${ }^{1}$ Zoran Gligorić1 ${ }^{1}$ Zoran Gojković ${ }^{1}$, Aleksandar Ganić1
}

Received: April 15, 2020

Accepted: June 8, 2020

\begin{abstract}
The Grey Model (GM) is a powerful tool in the Grey System Theory for estimating the behavior of partially unknown systems or systems with limited information. In the Grey System Theory, $\operatorname{GM}(1,1)$ is the most widely used model for prediction. The applicability of this model for the purpose of buildings deformation forecasting in a vertical plane was tested on the case of the deformation forecasting of the building of Faculty of Mining and Geology in Belgrade. The non-equidistance grey model $(1,1)$ was utilized, since the measurements on which the model was formed, were performed in various time intervals.
\end{abstract}

Keywords: The Grey Model; forecasting; deformation;

\section{INTRODUCTION}

In the research of any system behavior analysis, application of the correct mathematical and evaluation methods based on the available information are very important. If we take into consideration the behavior of monitored system is uncertain, as a result of unclear effects of other systems influencing the system being analyzed, then capability to forecast the future states of the system can have the key role to prevent the collapse of the system.

A system whose information is completely clear is called a white system. A system whose information is not clear at all is called a black system (a black box). And a system whose information is partly clear or partly unclear is called a grey system. In fact, incomplete information is the basic characteristic of the problems considered in grey systems theory (Lin, Chen \& Liu, 2004).

\footnotetext{
${ }^{1}$ University of Belgrade - Faculty of Mining and Geology

Emails: aleksandar.milutinovic@ @rgf.bg.ac.rs; zoran.gligoric@ @rgf.bg.ac.rs; zoran.gojkovic@ @rgf.bg.ac.rs; aleksandar.ganic@rgf.bg.ac.rs
} 
The Grey System Theory is proposed by Deng Julong in 1982, which has been widely used in many fields. The Grey System Theory deems that no matter how complex the objective system is, it is related with overall function. Therefore, the behavioral characteristics data always conceal some kinds of law, which could be found from the original data. Deal the original, non-random data and make it more regular, and then use the new data to establish corresponding model, which provides a new way to solve the problem of poor information (Deng, 1982).

The Grey Model (GM) is a powerful tool in the Grey System Theory for estimating the behavior of partially unknown systems or systems with limited information (Deng, 1989). In the Grey System Theory, $\operatorname{GM}(1,1)$ is the most widely used model for prediction. The first parameter in the bracket of $\operatorname{GM}(1,1)$ denotes the order of differential equation, and the second parameter indicates the number of variables (Yang, Chen \& $\mathrm{Lu}$, 2012).

The applicability of The Grey Model for the purpose of buildings deformation forecasting in a vertical plane was tested and analyzed on the case of the deformation forecasting of the building of Faculty of Mining and Geology in Belgrade. In total, 12 line benchmarks were stabilized for which the altitudes were geodetically measured. Between 2013 and 2019, in various time intervals a total of seven measurement series were performed. Seven series of the calculated altitudes for 12 operating benchmarks were used to create a non-equidistance grey model $(1,1)$, as well as to perform the necessary analyses.

\section{BRIEF DESCRIPTION OF NON-EQUIDISTANCE GREY MODEL $(1,1)$}

The Grey System Model is mostly based on the equidistance sequence; however, the original data obtained in the practical work is mostly based on the non-equidistant sequence; therefore, the establishment of non-equidistant sequence model has the certain practical and theoretical significances (Zou, Mou \& Yi, 2012).

Definition 1: Suppose that $X^{(0)}=\left\{x^{(0)}\left(t_{1}\right), x^{(0)}\left(t_{2}\right), \ldots, x^{(0)}\left(t_{n}\right),\right\}$ is original time series of real numbers with irregular distribution, where $x^{(0)}\left(t_{k}\right)$ is the system output data at time tk. If sampling interval $\Delta t_{k}=t_{k}-t_{k-1} \neq$ constant, $2 \leq k \leq n$, then $x^{(0)}$ is called non-equidistance time series.

Non-equidistance Grey Model $\operatorname{NGM}(1,1)$ which stand for a single variable first order differential equation prediction model based on the Grey System Theory has already been proposed to predict and analyze the non-equidistance data series from uncertain system (Deng, 1985; Nagai \& Yamaguchi, 2004).

The basic concept of NGM is described as follows. Consider a time series with $\mathrm{n}$ data points, 


$$
X^{(0)}=\left\{x^{(0)}(1), x^{(0)}(2), \ldots, x^{(0)}(n),\right\}
$$

where the superscript $(0)$ denotes the original time series and $x^{(0)}(k)$ represents the $\mathrm{k}$-th data point. Note, the $X^{(0)}=\left\{x^{(0)}(1), x^{(0)}(2), \ldots, x^{(0)}(n),\right\}$ is non-negative time series and $n \geq 4$. The following procedures address the process of using $\operatorname{NGM}(1,1)$ to make a one-step ahead prediction based on the Reciprocal Accumulated Generating Operation.

Definition 2: According to Definition 1, we can define reciprocal output data as follows:

$$
y^{(0)}\left(t_{k}\right)=\frac{1}{x^{(0)}\left(t_{k}\right)}, \quad k=1,2, \ldots, n
$$

Then, $Y^{(0)}=\left\{y^{(0)}\left(t_{1}\right), y^{(0)}\left(t_{2}\right), \ldots, y^{(0)}\left(t_{n}\right)\right\}$ should be referred to as the reciprocal time series of $X^{(0)}$.

Definition 3: If

$$
\left\{\begin{array}{c}
y^{(1)}\left(t_{1}\right)=y^{(0)}\left(t_{1}\right) \\
y^{(1)}\left(t_{k+1}\right)=y^{(1)}\left(t_{k}\right)+y^{(0)}\left(t_{k+1}\right) \cdot \Delta t_{k+1}, \quad k=1,2, \ldots, n-1
\end{array}\right.
$$

then $Y^{(1)}$ should be referred to as the first order reciprocal accumulated generating operation (AGO) of non-equidistance time series $X^{(0)}$.

In order to establish the model, the one-order reciprocal accumulated generating operation shall be carried out firstly for the original data as follows:

$$
y^{(1)}\left(t_{k}\right)=\left\{\begin{array}{c}
y^{(0)}\left(t_{1}\right)+\sum_{i=1}^{k} y^{(1)}\left(t_{i}\right) \cdot\left(t_{i}-t_{i-1}\right), k=2,3, \ldots, n \\
y^{(0)}\left(t_{1}\right), \quad k=1
\end{array}\right.
$$

According to equation (4), a new time series is defined by following set:

$$
Y^{(1)}=\left\{y^{1}\left(t_{1}\right), y^{1}\left(t_{2}\right), \ldots, y^{1}\left(t_{n}\right)\right\}
$$


The non-equidistance grey prediction $\operatorname{NGM}(1,1)$ model can be described by one variable, and first order differential equation.

$$
\frac{d y^{(1)}}{d t}+a y^{(1)}=b
$$

The solution of equation (6) can be obtained by Laplace transform ( $\mathrm{Li}$, Yamaguchi \& Nagai, 2005). By Laplace transform, equation (6) can be expressed in frequency domain as (Li, Yamaguchi \& Nagai, 2006):

$$
s y^{(1)}(s)-u(0)+a y^{(1)}(s)=\frac{b}{s}
$$

where $\mathrm{u}(0)$ is initial value of system at $\mathrm{t}=0$. Initial value is $u(0)=y^{(0)}\left(t_{1}\right)=y^{(1)}\left(t_{1}\right)$. The solution of equation (7) is as follows:

$$
y^{(1)}(s)=\frac{u(0)-\frac{b}{a}}{s+a}+\frac{\frac{b}{a}}{s}
$$

By Laplace inversion transform, the solution of discrete system form are obtain by:

$$
\hat{y}^{(1)}\left(t_{k}\right)=\left(y^{(0)}\left(t_{1}\right)-\frac{b}{a}\right) e^{-a\left(t_{k}-t_{1}\right)}+\frac{b}{a}, \quad k=1,2, \ldots, n
$$

where the coefficients a and bare called developing and grey input coefficient, respectively.

These coefficients are defined by least-square of $\operatorname{NGM}(1,1)$ based on the reciprocal accumulated generating operation as follows:

$$
\left[\begin{array}{l}
a \\
b
\end{array}\right]=\left(A^{T} A\right)^{-1} A^{T} B
$$


Where:

$$
A=\left[\begin{array}{cc}
-\frac{1}{2}\left(y^{(1)}\left(t_{2}\right)+y^{(1)}\left(t_{1}\right)\right) & 1 \\
-\frac{1}{2}\left(y^{(1)}\left(t_{3}\right)+y^{(1)}\left(t_{2}\right)\right) & 1 \\
\vdots & \vdots \\
-\frac{1}{2}\left(y^{(1)}\left(t_{n}\right)+y^{(1)}\left(t_{n-1}\right)\right) & 1
\end{array}\right], \quad B=\left[\begin{array}{c}
y^{(0)}\left(t_{2}\right) \\
y^{(0)}\left(t_{3}\right) \\
\vdots \\
y^{(0)}\left(t_{n}\right)
\end{array}\right]
$$

The fitted value of the reciprocal of original data gained after reduction is:

$$
\hat{y}^{(0)}\left(t_{k}\right)=\left\{\begin{array}{c}
y^{(0)}\left(t_{1}\right), \quad k=1 \\
\frac{\left(y^{(0)}\left(t_{1}\right)-\frac{b}{a}\right)\left(1-e^{\left.\Delta t_{k}\right)}\right.}{\Delta t_{k}}, k=2,3, \ldots, n
\end{array}\right.
$$

From equation (12), the data series $\left\{\hat{y}^{(0)}\left(t_{1}\right), \hat{y}^{(0)}\left(t_{2}\right), \ldots, \hat{y}^{(0)}\left(t_{n+q}\right), q \geq 1\right\}$ are called reciprocal predicted data series. The value of original data series is obtained according to Definition 2, i.e.:

$$
\hat{x}^{(0)}\left(t_{k}\right)=\frac{1}{\hat{y}^{(0)}\left(t_{k}\right)}, k=1,2, \ldots, n
$$

The absolute error of predicted data is given by the following equation:

$$
\epsilon\left(t_{k}\right)=\hat{x}^{(0)}\left(t_{k}\right)-x^{(0)}\left(t_{k}\right)
$$

The relative error of predicted data is given by the following equation:

$$
\delta\left(t_{k}\right)=\frac{\hat{x}^{(0)}\left(t_{k}\right)-x^{(0)}\left(t_{k}\right)}{x^{(0)}\left(t_{k}\right)} \times 100 \%
$$


The mean absolute error of predicted data is given by the following equation:

$$
M A E=\frac{1}{n}\left|\sum_{k=1}^{n} \delta\left(t_{k}\right)\right|
$$

\section{CASE STUDY}

The building of the Faculty of Mining and Geology is situated in the broader center of Belgrade, in a block limited by the following streets: Takovska, Dalmatinska, Djusina and 27. marta (Figure 1). The building was constructed in 1929, many times it purpose was changed, and the Faculty is located in it since 1952.

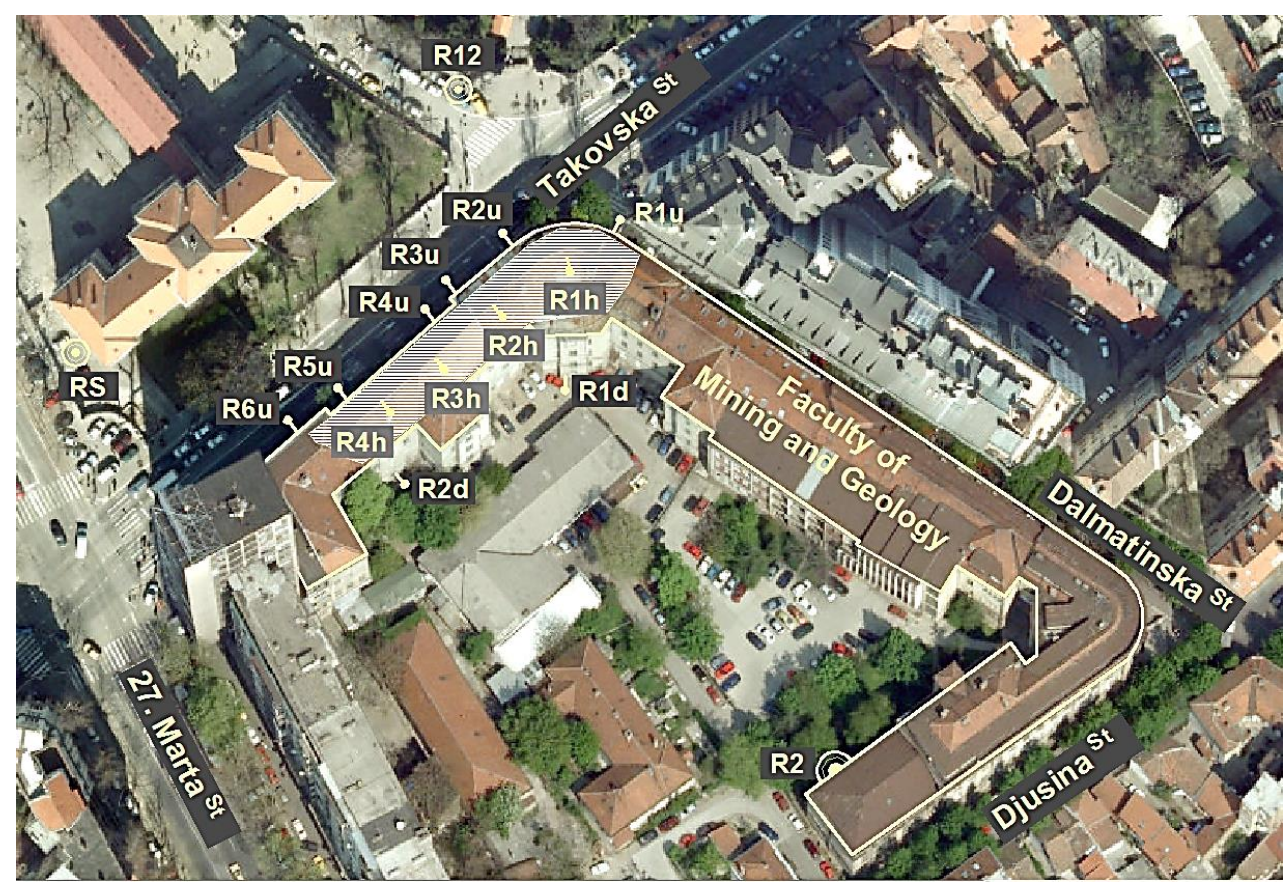

Figure 1 Building of the Faculty of mining and geology with the distribution of basic and operating benchmarks

The age of the building, and the way of construction, geological composition of the soil, the intense traffic and the tram, trolley and bus public transport going through the Takovska and the 27. marta streets, as well as timeworn plumbing and sewer networks typical for this part of town have caused the cleavages to occur on the wing of the building in the Takovska street (Figure 2). 


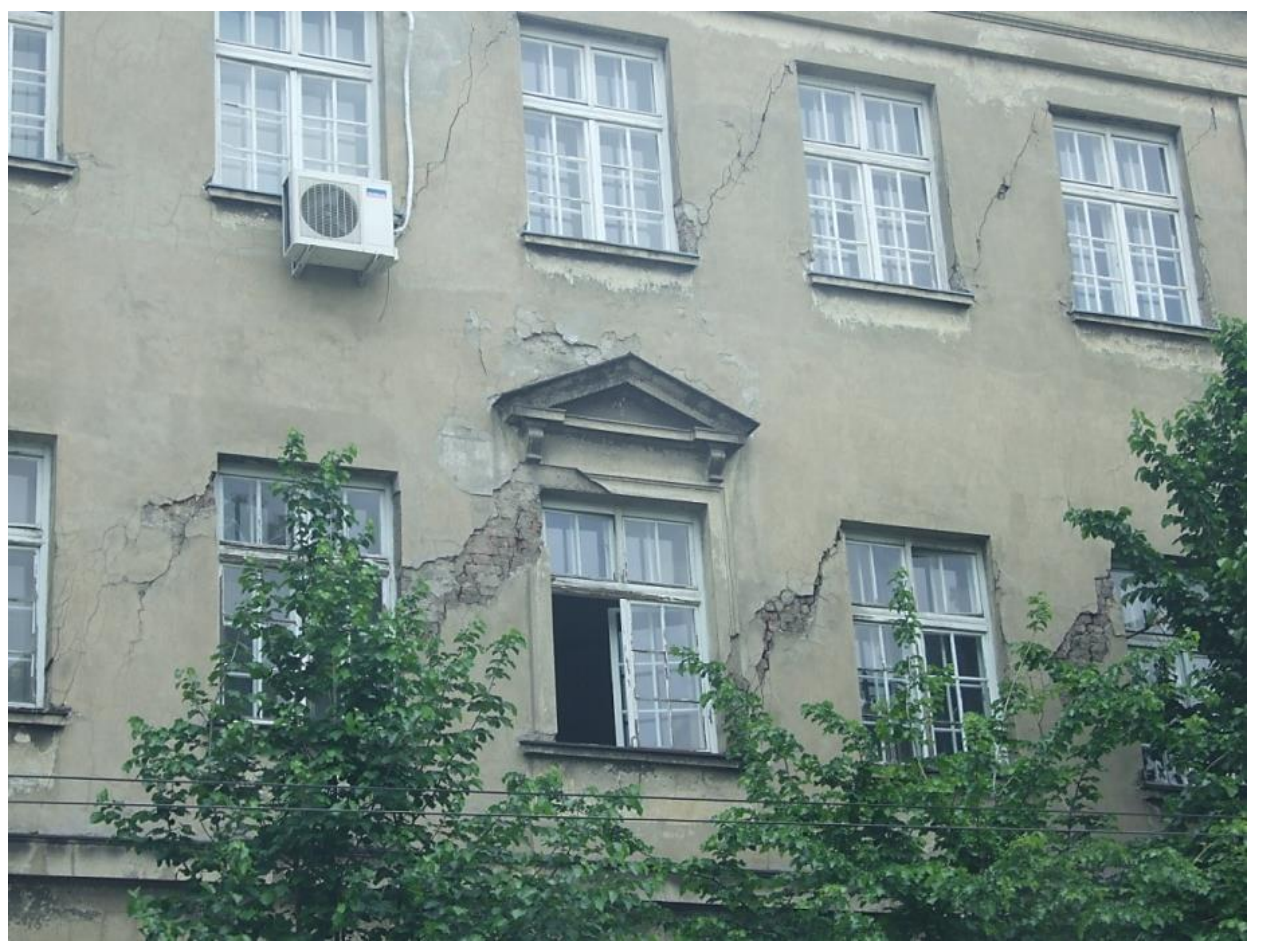

Figure 2 The look of the front of the Faculty of Mining and Geology building in the Takovska street.

In order to test the deformations of the building in a vertical plane, a total of 12 operating benchmarks were set: 6 on the street side of the building, 4 in the ground hall of the building and 2 in the courtyard side. The operating benchmarks were connected with the three basic state benchmarks with known altitudes, and so the levelling network for deformation measurements was made by 15 benchmarks overall (Fig. 1). By geodetic methods of measuring the altitude differences and the indirect equalization method, the most probable altitudes values of operating benchmarks are determined.

The first series of measurements was performed on October 30th, 2013, while the last, the seventh was performed on June 17th, 2019. Time intervals between the measurement series varied.

The non-equidistance grey model $(1,1)$ for the purpose of forecasting the variations in operating benchmarks altitudes, i.e. the vertical plane deformations, was created on the basis of six series of measurements performed between October 2013 and October 2016. The values of the operating benchmarks altitudes and their standard deviations for the first six series of measurements, based on which the model was created, are given in Table 1. 
Milutinović A., Gligorić Z., Gojković Z., Ganić A.

Table 1 Altitudes of the operating benchmarks

\begin{tabular}{|c|c|c|c|c|c|c|c|c|c|c|c|c|}
\hline \multirow{2}{*}{$\begin{array}{c}\text { Series } \\
\text { Date }\end{array}$} & \multicolumn{2}{|l|}{1} & \multicolumn{2}{|l|}{2} & \multicolumn{2}{|l|}{3} & \multicolumn{2}{|l|}{4} & \multicolumn{2}{|l|}{5} & \multicolumn{2}{|l|}{6} \\
\hline & $10 / 30 / 2$ & 013 & $11 / 30 / 2$ & 013 & $05 / 27 / 2$ & 014 & $11 / 05 / 2$ & 014 & $04 / 01 / 2$ & 015 & $10 / 03 / 2$ & 016 \\
\hline \multirow{2}{*}{ Benchmark } & $\mathrm{H}$ & $\sigma$ & $\mathrm{H}$ & $\sigma$ & $\mathrm{H}$ & $\sigma$ & $\mathrm{H}$ & $\sigma$ & $\mathrm{H}$ & $\sigma$ & $\mathrm{H}$ & $\sigma$ \\
\hline & {$[\mathrm{m}]$} & {$[\mathrm{mm}]$} & {$[\mathrm{ml}$} & {$[\mathrm{mm}]$} & {$[\mathrm{m}]$} & {$[\mathrm{mm}]$} & {$[\mathrm{m}]$} & {$[\mathrm{mm}]$} & {$[\mathrm{m}]$} & {$[\mathrm{mm}]$} & {$[\mathrm{m}]$} & {$[\mathrm{mm}]$} \\
\hline $\mathrm{R} 1 \mathrm{u}$ & 101.2206 & 1.53 & 101.2229 & 2.54 & 101.2244 & 1.97 & 101.2197 & 2.18 & 101.2223 & 1.76 & 101.2246 & 1.12 \\
\hline $\mathrm{R} 2 \mathrm{u}$ & 101.3588 & 1.62 & 101.3604 & 2.69 & 101.3607 & 2.09 & 101.3581 & 2.30 & 101.3584 & 1.86 & 101.3621 & 1.19 \\
\hline $\mathrm{R} 3 \mathrm{u}$ & 101.6526 & 1.64 & 101.6540 & 2.72 & 101.6536 & 2.11 & 101.6505 & 2.33 & 101.6514 & 1.88 & 101.6531 & 1.20 \\
\hline $\mathrm{R} 4 \mathrm{u}$ & 101.8015 & 1.64 & 101.8014 & 2.71 & 101.7995 & 2.10 & 101.8000 & 2.32 & 101.8024 & 1.88 & 101.8009 & 1.20 \\
\hline $\mathrm{R} 5 \mathrm{u}$ & 102.7455 & 1.48 & 102.7460 & 2.45 & 102.7452 & 1.91 & 102.7438 & 2.11 & 102.7436 & 1.70 & 102.7449 & 1.09 \\
\hline R6u & 103.3529 & 1.44 & 103.3541 & 2.39 & 103.3531 & 1.85 & 103.3523 & 2.04 & 103.3511 & 1.65 & 103.3534 & 1.06 \\
\hline R1h & 103.2084 & 1.91 & 103.2105 & 3.17 & 103.2084 & 2.46 & 103.2077 & 2.72 & 103.2081 & 2.20 & 103.2103 & 1.40 \\
\hline $\mathrm{R} 2 \mathrm{~h}$ & 103.5167 & 1.90 & 103.5172 & 3.15 & 103.5163 & 2.44 & 103.5158 & 2.70 & 103.5149 & 2.18 & 103.5178 & 1.39 \\
\hline R3h & 103.4131 & 1.84 & 103.4152 & 3.06 & 103.4129 & 2.37 & 103.4123 & 2.62 & 103.4120 & 2.12 & 103.4153 & 1.35 \\
\hline $\mathrm{R} 4 \mathrm{~h}$ & 103.3574 & 1.66 & 103.3589 & 2.76 & 103.3577 & 2.14 & 103.3568 & 2.37 & 103.3568 & 1.91 & 103.3588 & 1.22 \\
\hline R1d & 102.2271 & 1.81 & 102.2290 & 3.00 & 102.2277 & 2.33 & 102.2273 & 2.57 & 102.2275 & 2.08 & 102.2299 & 1.33 \\
\hline $\mathrm{R} 2 \mathrm{~d}$ & 102.8965 & 1.80 & 102.8986 & 2.98 & 102.8967 & 2.31 & 102.8971 & 2.56 & 102.8962 & 2.06 & 102.8980 & 1.32 \\
\hline
\end{tabular}

The seventh series of measurements that serves as the model testing data was performed more than 2.5 years later (June 17th, 2019). For the date when the seventh series was performed, the benchmarks altitudes were forecasted according to the model created on the basis of the first six series of measurements and their comparison with the measured values was performed (Table 2). 
Forecasting the building deformation using the non-equidistance...

Table 2 Comparative values of the measured and the forecasted altitudes of operating benchmarks.

\begin{tabular}{cccc}
\hline Series & \multicolumn{2}{c}{7} \\
\hline Date & \multicolumn{2}{c}{$06 / 17 / 2019$} & \\
Benchmark & $\mathrm{H}_{\text {meas }}$ & $\mathrm{H}_{\text {forec }}$ & $\Delta=\mathrm{H}_{\text {meas }}-\mathrm{H}_{\text {forec }}$ \\
R1u & {$[\mathrm{m}]$} & {$[\mathrm{m}]$} & {$[\mathrm{mm}]$} \\
$\mathrm{R} 2 \mathrm{u}$ & 101.2215 & 101.2259 & -3.5 \\
$\mathrm{R} 3 \mathrm{u}$ & 101.6528 & 101.3616 & -1.7 \\
$\mathrm{R} 4 \mathrm{u}$ & 101.8027 & 101.6511 & +1.7 \\
$\mathrm{R} 5 \mathrm{u}$ & 102.7445 & 102.7434 & +2.0 \\
$\mathrm{R} 6 \mathrm{u}$ & 103.3518 & 103.3524 & +1.1 \\
$\mathrm{R} 1 \mathrm{~h}$ & 103.2101 & 103.2089 & +1.6 \\
$\mathrm{R} 2 \mathrm{~h}$ & 103.5162 & 103.5173 & -1.1 \\
$\mathrm{R} 3 \mathrm{~h}$ & 103.4125 & 103.4150 & -2.5 \\
$\mathrm{R} 4 \mathrm{~h}$ & 103.3581 & 103.3578 & +0.3 \\
$\mathrm{R} 1 \mathrm{~d}$ & 102.2296 & 102.2291 & +0.5 \\
$\mathrm{R} 2 \mathrm{~d}$ & 102.8978 & 102.8968 & +1.0 \\
\hline
\end{tabular}

The highest observed value of difference between the measured and the forecasted altitude is $3.5 \mathrm{~mm}$, for the benchmark R1u, the lowest is $0.3 \mathrm{~mm}$ for the benchmark R $4 \mathrm{~h}$, with the average difference of $1.4 \mathrm{~mm}$. The average difference between the measured and the forecasted values of altitudes are demonstrating the applicability of the mathematical model with grade evaluation good (Kose \& Tasci, 2015; Tseng, Yu \& Tzeng, 2001).

A chart of the measurement and forecasting altitudes curves for the benchmark R3u is given in Figure 3.

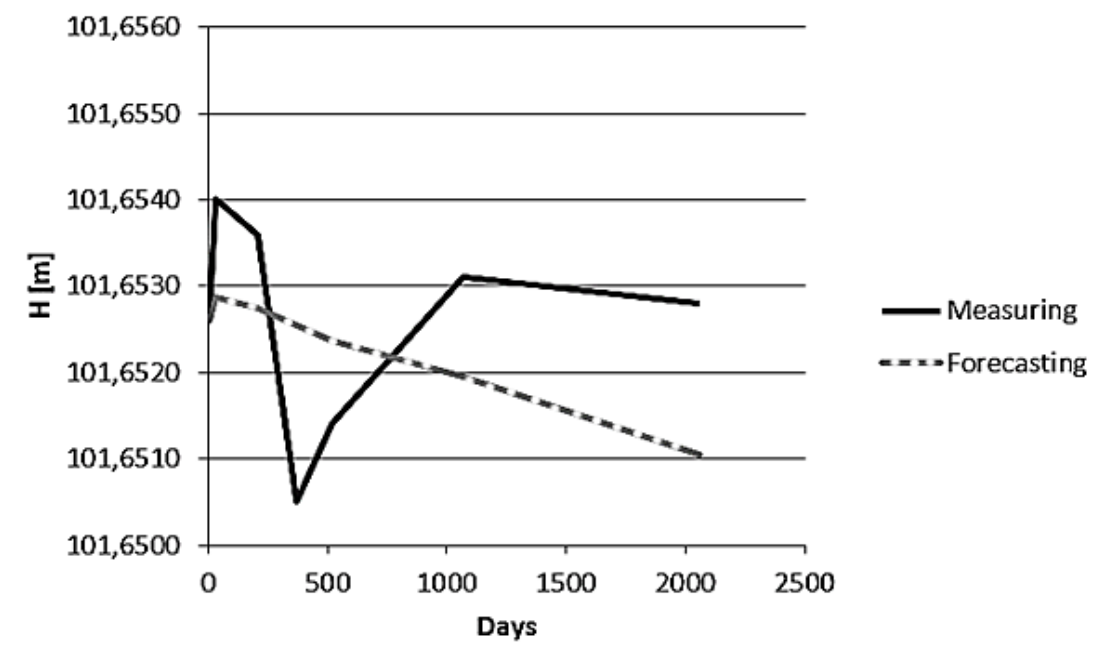

Figure 3 Forecasting of the operating benchmark R3u altitude based on the six series of measurements. 
The higher number of measurement series increases the model quality, thus making the prognosticated altitude values more realistic. In addition, measurement series must have a time distance defined in relation to the object type, deformation dynamics and consequences of deformations on the object itself but also on the infrastructure in the immediate proximity. Figure 4 shows the chart of the forecasted altitudes values curves developed according to the model created on the basis of all seven performed measurements of the same operating benchmark R3u.

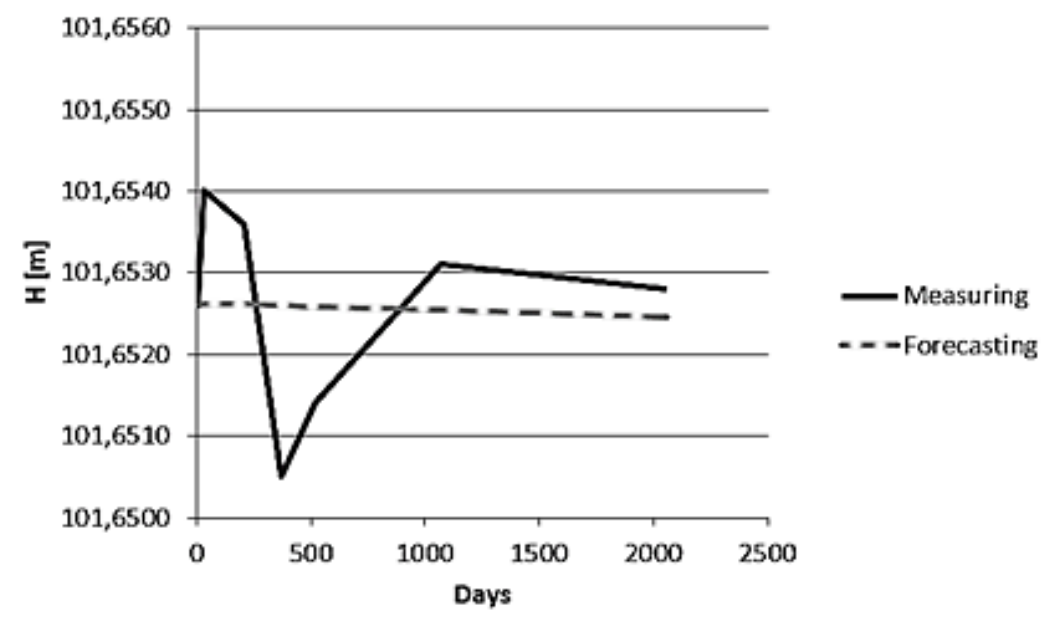

Figure 4 Forecasting of the operating benchmark R3u altitude based on the seven series of measurements.

The non-equidistance grey model $(1,1)$ based on all seven measurements performed so far, shows that the probable altitude of the benchmark R3u on the date of December, 31 st, 2020 will be $101.6524 \mathrm{~m}$.

\section{CONCLUSION}

The non-equidistance grey model $(1,1)$ created for the purpose of forecasting the deformation of the object in question at the vertical plane, showed its applicability for the given case. The model developed on the basis of six measurement series, tested after 2.5 years by a seventh measurement series is presenting satisfactory precision, having in mind that the maximum difference value between the measured and the forecasted altitude of the benchmark was $3.5 \mathrm{~mm}$ (benchmark R1u), the minimum $0.3 \mathrm{~mm}$ (benchmark R4h), and the average difference only $1.4 \mathrm{~mm}$.

The process of building deformation is not a constant process with the constant dynamics. Under the various external influences, the process can be more intense in some weather intervals, and in some stagnating. Therefore, it is necessary to update the model after every measurements series, thus creating the grounds for the better forecasting of operating benchmark altitudes in the future. 
The forecasted values of the vertical deformations of the benchmarks obtained by this model are the grounds for the analysis of deformation of this building in the future. Based on this analysis, timely activities can be taken regarding the planning of measurement dynamics, and in case the forecast shows that displacements that can endanger the statics of the building can occur, necessary civil construction operation should take place in order to stop the building deformations.

The non-equidistance grey model $(1,1)$ can be used in deformation measurements, not only at the building as shown in this case, but on the dams, disposal locations, waste dumps, landslides and other natural and technical objects subject to deformations.

\section{REFERENCES}

DENG, J L. (1982) Control problems of grey systems. The Journal Systems and Control Letters, 1(5), pp. 288-294.

DENG, J L. (1985) Grey System Control. Huazhong Univ. of Sci. and Technol, Press, pp. 25-134.

DENG, J L. (1989) Introduction to Grey system theory. The Journal of Grey System, 1(1), pp. 1-24.

KOSE, E. and TASCI, L. (2015) Prediction of the Vertical Displacement on the Crest of Keban Dam. The Journal of Grey System 2015; 27(1): 12-20.

LI, G D., YAMAGUCHI, D. and NAGAI, M. (2005) New methods and accuracy improvement of GM according to Laplace transform. The Journal of Grey System, 8(1), pp. 13-25.

LI, G D., YAMAGUCHI, D. and NAGAI, M. (2006) Non-Equidistance Grey Model Based on Grey Interval Weighting Accumulated Generating Operation. Proceedings of the International Conference on Machine Learning; Models, Technologies \& Applications, Las Vegas, Nevada, USA, pp. 180-188.

LIN, Y., CHEN, M. and LIU, S. (2004) Theory of grey systems: capturing uncertainties of grey information. Kybernetes; 33(2), pp. 196-218.

NAGAI, M. and YAMAGUCHI, D. (2004) Grey Theory and Engineering Application Method. Kyoritsu publisher.

TSENG, F M., YU, H C. and TZENG, G H. (2001) Applied hybrid grey model to forecast seasonal time series. Technological Forecasting and Social Change, 67(2), pp. 291-302.

YANG, Y W., CHEN, W H. and LU H P. (2012) A Fuzzy-Grey Model for Nonstationary Time Series Prediction. Applied Mathematics \& Information Sciences, An International Journal, 6(2S), pp. 445S-451S.

ZOU, R., MOU, Z. and YI W. (2012) The Non-Equidistant Grey GRM $(1,1)$ Model and Its Application. International Journal of Modern Nonlinear Theory and Application, 1(2), pp. 51-54. 